\title{
CORRECTION
}

\section{Correction to: Circular RNA hsa_circ_0000034 accelerates retinoblastoma advancement through the miR-361-3p/ADAM19 axis}

\author{
Yanhua Jiang ${ }^{1} \cdot$ Fan Xiao $^{1} \cdot$ Lin Wang $^{1} \cdot$ Ting Wang $^{1} \cdot$ Linlin Chen $^{1}(\mathbb{C}$ \\ Published online: 21 January 2022 \\ ○) Springer Science+Business Media, LLC, part of Springer Nature 2022

\section{Correction to: \\ Molecular and Cellular Biochemistry (2021) 476:69-80 \\ https://doi.org/10.1007/s11010-020-03886-5}

In the original publication of the article, title was published incorrectly. The correct title is provided in this correction.

Publisher's Note Springer Nature remains neutral with regard to jurisdictional claims in published maps and institutional affiliations.

The original article can be found online at https://doi.org/10.1007/ s11010-020-03886-5.

Linlin Chen

rkymlkz@163.com

1 Department of Ophthalmology, The Fourth People's Hospital of Shenyang, No. 20 Huanghe South Street, Huanggu District, Shenyang 110031, Liaoning, China 